\title{
Bispacer Multi-Stage Direct Contact Membrane Distillation System: Analytical and Experimental Study
}

\author{
Morteza Aliabadi ${ }^{1}$, Hassan Ghorashi ${ }^{1}$, Shamim Shokri Motlagh ${ }^{1}$, Seyedeh Fatemeh Nabavi ${ }^{2}$, \\ Seyed Arash Pakzad ${ }^{1}$, Mohamad Hossein Farshidianfar ${ }^{2, *}$, Anooshiravan Farshidianfar ${ }^{2}$, Farzaneh Mahmoudi ${ }^{3}$ \\ and Aliakbar Akbarzadeh ${ }^{3}$ \\ 1 Taha Ghaleb Toos Co., Mashhad 1696700, Iran; m.aliabadi@tgt-phe.com (M.A.); \\ ghorashi1379@um.ac.ir (H.G.); s.shokri@tgt-phe.com (S.S.M.); a.pakzad@tgt-phe.com (S.A.P.) \\ 2 Mechanical Engineering Department, Ferdowsi University of Mashhad, Mashhad 1696700, Iran; \\ S.fa.nabavi@mail.um.ac.ir (S.F.N.); farshid@um.ac.ir (A.F.) \\ 3 Mechanical and Automotive Engineering, School of Engineering, RMIT University, Bundoora, \\ Melbourne 3083, Australia; farzaneh.mahmoudi@rmit.edu.au (F.M.); aliakbar.akbarzadeh@rmit.edu.au (A.A.) \\ * Correspondence: farshidinafar@um.ac.ir
}

check for updates

Citation: Aliabadi, M.; Ghorashi, H.; Shokri Motlagh, S.; Nabavi, S.F.; Pakzad, S.A.; Farshidianfar, M.H.; Farshidianfar, A.; Mahmoudi, F.; Akbarzadeh, A. Bispacer Multi-Stage Direct Contact Membrane Distillation System: Analytical and Experimental Study. Processes 2021, 9, 1297. https://doi.org/10.3390/pr9081297

Academic Editor: Iqbal M. Mujtaba

Received: 28 May 2021

Accepted: 16 July 2021

Published: 27 July 2021

Publisher's Note: MDPI stays neutra with regard to jurisdictional claims in published maps and institutional affiliations.

Copyright: (c) 2021 by the authors. Licensee MDPI, Basel, Switzerland. This article is an open access article distributed under the terms and conditions of the Creative Commons Attribution (CC BY) license (https:// creativecommons.org/licenses/by/ $4.0 /)$
Abstract: A multi-staged direct contact membrane distillation (MDCMD) system is designed considering a novel bispacer configuration in the present study. The proposed bispacer DCMD, which has not been addressed in the literature to best of our knowledge, is considered with two purposes, including increasing mechanical stability and turbulence. As increasing turbulence leads to increasing Nusselt number, the bispacer MDCMD provides higher permeate flux. An analytical approach is considered using energy and mass balance correlation. The effect of bispacer and feed operating conditions, including feed temperature, feed flow rate, feed salinity, and the number of stages on permeate flux and salt rejection of the developed MDCMD, are examined both analytically and experimentally. The performance and sustainability of the developed system were investigated by analyzing the parameters, including thermal efficiency $(\eta)$, gained output ratio (GOR), and temperature polarization coefficient (TPC).

Keywords: direct contact membrane distillation; bispacer; multi-staged; permeate flux; GOR; thermal efficiency

\section{Introduction}

Many countries worldwide suffer from freshwater shortages due to vast population growth and lack of natural water resources. Reports have indicated an increase of $2 \%$ in freshwater demand with almost a doubling of population growth rates [1]. Therefore, clean water is a critical international problem, which should be addressed comprehensively in more studies. Hence, desalination systems as an alternative water resource have been developed extensively to satisfy the current demand and overcome the shortage.

Membrane distillation (MD) is a thermal based technology, which can be used for the desalination of saline feed. Based on the vapor pressure gradient created across the hydrophobic membrane, clean water can be extracted [2]. A temperature difference across a hydrophobic membrane in MD systems creates partial vapor difference as a driving force. It leads to water molecule evaporation at the hot side, transporting across the membrane in the vapor phase, and finally condensing at the cold side [3]. Membrane distillation is a non-isothermal process, and operation can be conducted at atmospheric pressure and produce highly pure water [4]. Hence, MD can be used at industrial sites where low heat and high salinity water are available. Consequently, membrane distillation technology is considered in the present study.

Various types of membrane distillation have been studied recently. Based on the method of withdrawing vapor from the hot side of the membrane, MD can be classified as direct contact membrane distillation (DCMD), air gap membrane distillation 
(AGMD), sweeping gas membrane distillation (SGMD), and vacuum membrane distillation (VMD) [5]. Among these configurations, the DCMD configuration has attracted a lot of attention, considering its simple design and higher pure water production rate [6]. In contrast, the VMD system has the benefit of higher energy efficiency compared to the DCMD design. It is noteworthy that although the energy efficiency of DCMD is lower than that of VMD systems, the ability to achieve higher permeate flux results in ignoring the lack of sufficient energy efficiency. Therefore, the present study has focused on the DCMD method $[7,8]$.

Different studies have investigated various processing parameters that affect the performance of the DCMD system [9,10]. Manawi et al. [11] have reported the feed flow rate and temperature effect on permeate flux of a single spacer and single-stage DCMD process with experimental and analytical studies. It was concluded that increases of both feed flow rate and temperature provide higher permeate flux. However, the effect of salinity and the number of stages were not addressed in their study. Khalifa et al. [12] considered the effect of feed temperature on permeate flux with single spacer and single-stage DCMD. Both experimental and analytical models showed that an increase in feed temperature leads to an increase of permeate flux in single spacer and single DCMD. Additionally, the effect of salinity, feed flow rate, and the number of stages was not considered in their study. Therefore, a comprehensive study that considers the influence of all inlet parameters on permeate flux in bispacer and multi-stage DCMD is needed.

The spacer in DCMD has been used to support the membrane as well as increase the feed stream turbulence. As an increase in turbulence leads to permeate flux enhancement, the effect of the spacer on DCMD performance is unavoidable. Hence, some studies address the influence of spacers on DCMD operation. Zhang et al. [13] presented an analytical model, which considers the characteristics of the spacer in single-stage DCMD. It is worth noting that the local Nusselt number was used in the presented spacer model, which was calculated from the turbulent flow. It was revealed that the error between the presented model and experimental was less than $10 \%$ in single spacer DCMD with respect to feed temperature. Moreover, the effect of flow rate and salinity on error was not reported in their study. The experimental investigation of heat transfer on single stage and single spacer DCMD flow channels with and without a spacer was studied by Linh Ve et al. [14]. Different kinds of spacers were proposed considering materials including plastic, stainless steel, fiberglass, and aluminum with woven and non-woven structures. The analytical model was conducted for the single non-woven plastic spacer. Although the proposed model was beneficial for predicting the single spacer DCMD, the effect of a bispacer was not considered. Further study was reported to analyze the effect of feed inlet temperature and feed concentration on mass transfer in single spacer and single-stage DCMD for proposed spacers [15]. It was concluded that mass transfer characteristics were affected by polymerbased spacers significantly. Although the effect of the spacer and its material and geometry were studied previously, using bispacer multi-staged DCMD was not addressed.

DCMD technology can be used both in single and multi-stage configurations called MDCMD. It has been shown that an increase in membrane surface area leads to an increase in thermal efficiency at a constant flow rate [16]. Hence, as none of the previous studies addressed the effect of bispacer MDCMD, it is considered in the present study.

The purposes of spacer usage in DCMD systems include (1) increasing mechanical stability, and (2) increasing turbulence. Hence, two spacers can be proposed in DCMD to emphasize each purpose separately. Here, using a combination of two spacers with different geometrical properties, an innovative bispacer multi-staged DCMD module was designed. Spacer 1 plays a significant role in the mechanical strength of the membrane in MDCMD, while spacer 2 was used to increase the turbulence of hot side streams. Mechanical stability improvement and turbulence enhancement of hot side streams facilitate the higher pressure and flowrate working operation. Furthermore, the temperature difference reduction between bulk fluid and membrane surface by increasing turbulence reduces the 
temperature polarization effect. Therefore, the permeate flux and thermal efficiency are increased compared to conventional MDCMD systems.

The MDCMD module under countercurrent flow is presented to study the effect of the proposed bispacer configuration. This process is applicable for both large-scale and footprint desalination industrial sites. Thus, the objective of the present study is to investigate the effect of main feed parameters such as feed temperature, flow rate, salinity, and the number of stages on permeate flux, thermal efficiency and GOR of bispacer MDCMD analytical models in conditions with and without spacers.

In the present study, the analytical approach is presented in Section 2. Heat transfers of flow through three layers, including feed stream to the membrane boundary layer, the membrane, and membrane surface to the permeate stream were considered using conservation of energy correlations. The nonlinear model was solved using the iterative numerical method by MATLAB. The mass transfer model is presented considering the effect of bispacer properties. A counterflow MDCMD setup is presented in Section 3 to investigate the performance of the presented bispacer. The effect of feed temperature, flow rate, salinity, and the number of stages on the presented bispacer MDCMD are studied in Section 4. The efficiency of the proposed MDCMD is estimated using thermal efficiency, gained output ratio (GOR), temperature polarization coefficient, (TPC), and specific thermal energy consumption (STEC) parameters.

\section{Analytical Approach}

As can be seen in Figure 1, two mechanisms, including mass and heat transfer, occur simultaneously in DCMD. Firstly, the rate of heat transfer highly depends on the temperature gradient between the hot and cold parts or the driving force. Secondly, the partial vapor pressure difference due to the temperature difference between parts is the main reason for mass transfer. These mechanisms perform across both the feed and permeate boundary layers near the membrane surfaces and through it. In other words, the temperature difference between the feed/membrane interface temperature $\left(T_{m, f}\right)$ and the permeate/membrane interface temperature $\left(T_{m, p}\right)$ is the driving force for water vapor transfer through the membrane pores. Hence, a vapor pressure difference between membrane sides is created. This forces the vapor molecules to transfer through the membrane pores and condensate at the cold membrane side.

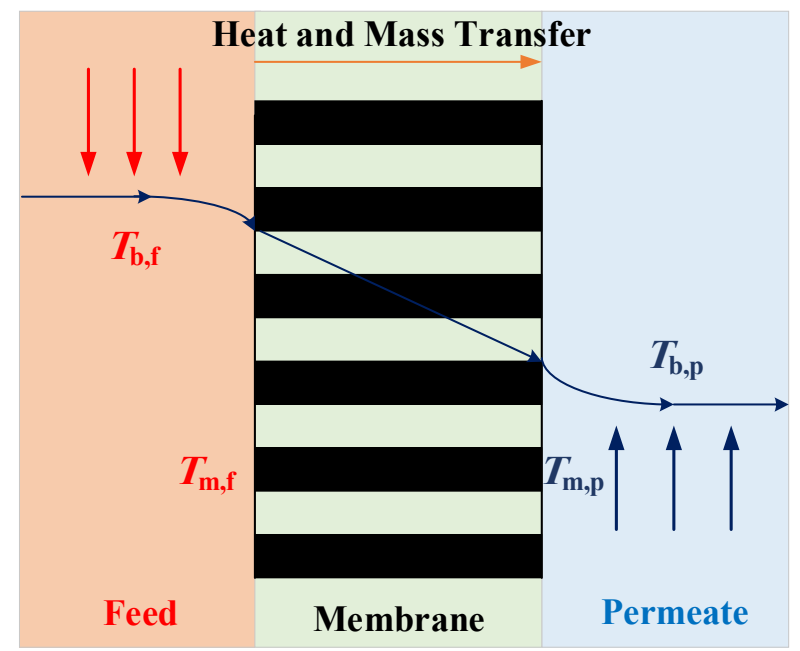

Figure 1. Heat and mass transfer through the membrane in the DCMD configuration.

An analytical investigation was considered to study the performance of the presented MDCMD module. The presented module was constructed based on the mass and heat transfer energy balance approach. Since these series equations are nonlinear, a numerical iterative technique was considered to solve them. It was assumed that the MDCMD was under steady-state conditions and the surrounding's heat loss was negligible. The 
percentage of salt removal was considered to be $100 \%$, and the passage of non-volatile particles was excluded. These assumptions have been noticed in previous studies [17]. The analytical model, which is based on both laminar and turbulent flow, is as follows.

\subsection{Heat Transfer Model}

Considering MDCMD model in Figure 1, three different models of heat transfer are recognized based on regions in which it has been transferred as follows:

\subsubsection{Heat Transfer: The Feed Stream to the Membrane Boundary Layer}

There is heat transfer through the feed stream to the membrane boundary layer. The convection-heat flux $\left(Q_{f}\right)$ in this layer is provided in Equation (1) [18]:

$$
Q_{f}=h_{f} \times\left(T_{b, f}-T_{m, f}\right)
$$

where $h_{f}, T_{b, f}$, and $T_{m, f}$ are the boundary layer heat transfer coefficient at the membrane feed layer, the average inlet and outlet temperature of the feed bulk, and the membrane surface temperature, respectively. The heat transfer coefficient of the boundary layer at the membrane feed layer $\left(h_{f}\right)$ is obtained in Equation (2) [19]:

$$
h_{f}=\frac{N u \times k}{d_{h}}
$$

where $k, d_{h}$, and $N u$ are the thermal conductivity of the fluid at the membrane feed layer, hydraulic diameter, and the Nusselt number, respectively. The Nusselt numbers $(\mathrm{Nu})$ for two flows including laminar and turbulent are given in Table 1.

Table 1. Nusselt number formula for different spacer conditions.

\begin{tabular}{cccc}
\hline Spacer Condition & With Spacer [14] & \multicolumn{2}{c}{ Without Spacer [19] } \\
\hline $\operatorname{Re}$ & All domain & $\operatorname{Re}<2100$ & $\operatorname{Re}>2500$ \\
\hline Nusselt number & $0.66 k_{d c} \operatorname{Re}^{0.5} \operatorname{Pr}^{0.33}\left(\frac{2 d_{h s}}{l_{m}}\right)^{0.5}$ & $1.86\left(\operatorname{RePr} \frac{d_{h}}{L}\right)^{0.33}$ & $0.023 \operatorname{Re}^{0.8} \operatorname{Pr}^{n}$ \\
\hline
\end{tabular}

Where Reynolds number (Re) and Prandtl number (Pr) are considered in Nusselt number. Further details about the above parameters are explained in Appendix A.

\subsubsection{Heat Transfer: Through the Membrane}

Heat is carried through membrane material by two mechanisms, including conduction $\left(Q_{c}\right)$ and evaporative heat flux $\left(Q_{v}\right)$. The evaporative heat flux is written as [20]

$$
Q_{v}=J \times \Delta H_{v}
$$

where $J$ is vapor mass flux. The enthalpy of water vaporization $\left(\Delta H_{v}\right)$ is as follows [20]:

$$
\Delta H_{v}=\left(1.7535 \times\left(\frac{T_{m, f}+T_{m, p}}{2}\right)\right)+2024.3
$$

Considering Fourier's law of conduction, conduction heat transfer through the membrane can be obtained as follows:

$$
Q_{c}=h_{m} \times\left(T_{m, f}-T_{m, p}\right)=\frac{k_{m}}{\delta} \times\left(T_{m, f}-T_{m, p}\right)
$$


where $\delta$ and $T_{m, p}$ are the membrane thickness and membrane surface temperature in the permeate layer, respectively. $h_{m}$ is the heat transfer coefficient of the membrane. The thermal conductivity of the membrane $\left(k_{m}\right)$ can be calculated as follows [20]:

$$
k_{m}=\left[\frac{\varepsilon}{k_{g}}+\frac{1-\varepsilon}{k_{s}}\right]^{-1}
$$

where $\varepsilon, k_{g}$, and $k_{s}$ are membrane porosity, gas thermal conductivity, and membrane polymer conductivity, respectively.

The total heat flux across the membrane is the sum of the conductive and evaporative heat transfer, $Q_{c}$ and $Q_{v}$, respectively, through the membrane:

$$
Q_{m}=Q_{c}+Q_{v}
$$

\subsubsection{Heat Transfer: The Membrane Surface to the Permeate Stream}

The convective heat flux in the boundary layer region from the membrane surface to the permeate bulk is defined as follows:

$$
Q_{p}=h_{p} \times\left(T_{m, p}-T_{b, p}\right)
$$

where $T_{b, p}$ is the permeate bulk temperature, and $h_{p}$ is the convective heat transfer coefficient in permeate side, which can be obtained similar to $h_{f}$ with respect to its permeate side conditions.

\subsubsection{Conservation Energy}

Considering steady state condition, the conservation of energy leads to

$$
Q_{f}=Q_{m}=Q_{p}
$$

Therefore, the temperatures of the membrane surfaces at the feed and permeate surface can be calculated as [21]

$$
\begin{aligned}
T_{m, f}= & \frac{h_{m}\left(T_{b, p}+\frac{h_{f}}{h_{p}} T_{b, f}\right)+h_{f} T_{b, f}-J H_{v}}{h_{m}+h_{f}\left(1+\frac{h_{m}}{h_{p}}\right)} \\
T_{m, p}= & \frac{h_{m}\left(T_{b, f}+\frac{h_{p}}{h_{f}} T_{b, p}\right)+h_{p} T_{b, p}+J H_{v}}{h_{m}+h_{p}\left(1+\frac{h_{m}}{h_{f}}\right)}
\end{aligned}
$$

The values of these temperatures can be calculated based on an iterative numerical approach, the details of which are provided in Appendix B.

\subsection{Mass Transfer Model}

Considering Figure 1, the vapor transfers from the feed side to permeate side because of partial vapor pressure difference force. It results from the temperature difference across the membrane. Both feed and permeate flows are kept under constant pressure (about 0.8 bar) inside the membrane module, so no transmembrane hydrostatic pressure is applied, and a Poiseuille-type mechanism of transport is negligible [22]. Considering these assumptions, the Dusty gas model is the most widely developed model to simulate mass transfer through the porous membrane [23]. Three main mass transfer mechanisms were studied in membrane cavities, including molecular diffusion, Knudsen, and Knudsenmolecular diffusion models. Hence, the type of mechanism can be selected based on the Knudsen number $(k n)$, as shown in Table 2. 
Table 2. Types of mass transfer mechanisms based on Knudsen number [13], Reproduced with permission from [Morteza Aliabadi], [Processes]; published by [MDPI AG], [2021].

\begin{tabular}{cc}
\hline Condition & Type of Flow Mechanism \\
\hline$k n<0.01$ & Molecular diffusion \\
$0.01<k n<1$ & Knudsen-molecular diffusion \\
$k n>1$ & Knudsen diffusion \\
\hline
\end{tabular}

The Knudsen number is defined as follows:

$$
k n=\frac{S}{d_{p}}
$$

where $d_{p}$ and $S$ are the mean pore diameter of the membrane and the mean free path of the transferred gas molecule, respectively. $S$ is defined as follows:

$$
S=\frac{k_{B} T_{m}}{\sqrt{2} \pi P d_{e}^{2}}
$$

where $k_{B}$ the coefficient of Stephen Boltzmann, $d_{e}$ is collision diameter, and $P$ is the mean vapor pressure within the membrane pore. $T_{m}$ is absolute temperature within the membrane pore. After calculating the Knudsen number, the mass transfer mechanism and mass transfer flux can be determined. The mass transfer is written as a linear function of partial vapor pressure difference and is defined by Khalifa et al. [12]:

$$
J=C_{m}\left(P_{1}-P_{2}\right)
$$

where $J$ is the mass flux. The partial vapor pressure evaluated at the membrane surface temperatures $T_{1}$ and $T_{2}$ are shown with $P_{1}$ and $P_{2}$, respectively [13] $C_{m}$ is the membrane mass transfer, which is different based on mass transfer mechanism as follows [17]:

$$
\begin{gathered}
C_{m}^{k}=\frac{2 \varepsilon r}{3 \tau \delta}\left(\frac{8 M}{\pi R T}\right)^{1 / 2} \quad k n<0.01 \\
C_{m}^{D}=\frac{\varepsilon}{\tau \delta} \frac{P D}{P_{a}} \frac{M}{R T} \quad 0.01<k n<1 \\
C_{m}^{C}=\left[\frac{3}{2} \frac{\tau \delta}{\varepsilon d}\left(\frac{\pi R T}{8 M}\right)+\frac{\tau \delta}{\varepsilon} \frac{P_{a}}{P D} \frac{R T}{M}\right]^{-1} \quad k n>1
\end{gathered}
$$

where $\tau$ is the membrane tortuosity $\left(\frac{(2-\varepsilon)^{2}}{\varepsilon}\right)$ [24], and $D$ is the water diffusion coefficient in air. The product of diffusivity of air and total pressure inside the pore, the partial pressure inside the pore, is defined by Essalhi et al. in Equation (18) [25].

$$
P D=1.895 \times 10^{-5} T_{m}^{2.072}
$$

The vapor pressure of pure water in permeate and feed boundaries with respect to corresponding permeate/feed membrane temperature can be obtained considering Antoine's Equation [26]:

$$
P_{p}^{0}=\exp \left(23.1964-\frac{3816.44}{T_{m, p}-46.13}\right)
$$

The vapor pressure of aqueous $\mathrm{NaCl}$ solution in the feed can be corrected by a correction factor obtained from the following equation [27]:

$$
\begin{gathered}
P_{f}=P_{f}^{0} a_{w}=p_{f}^{0} x_{w} \gamma_{i} \\
\gamma_{i}=1-0.5 x_{\mathrm{NaCl}}-10 x_{\mathrm{NaCl}}^{2}
\end{gathered}
$$


where $a_{W}, \gamma_{i}, x_{\mathrm{NaCl}}$, and $x_{W}$ are activity, coefficient of activity, the weight fraction of $\mathrm{NaCl}$ in saline solution, and the weight fraction of water, respectively

\subsection{MDCMD Module Efficiency}

To investigate operability and sustainability of the presented MDCMD, different output parameters are introduced and studied in this section as follows:

\subsubsection{Thermal Efficiency}

The thermal efficiency or $\eta$ is one of the parameters, which describes the operability of MDCMD, in previous studies. The ratio between the water thermal energy consumption to generate vapor and the total energy supplied to the system is defined as thermal efficiency as follows [28]:

$$
\eta(\%)=\frac{J \Delta H_{v}}{h_{m}\left(T_{m, f}-T_{m, p}\right)+J \Delta H_{v}} \times 100=1-\frac{h_{m}\left(T_{m, f}-T_{m, p}\right)}{h_{m}\left(T_{m, f}-T_{m, p}\right)+J \Delta H_{v}} \times 100
$$

\subsubsection{Gained Output Ratio (GOR)}

Gained output ratio is an alternative representation of the STEC of the system. Here, the ratio of the vapor heat transfer to the total input heat is defined as the gained output ratio or GOR. This parameter interprets how much of the total supplied thermal energy is usefully used in the production of the permeate flux. In DCMD desalination systems, the GOR must be $<1$ due to heat loss of conduction of the MD module. The GOR can be defined as [28]

$$
\text { GOR }=\frac{J \Delta H_{v} A}{m_{f} C_{p}\left(T_{b, f, \text { in }}-T_{b, f, \text { out }}\right)}
$$

where $A, m_{f}$, and $\mathrm{C}_{p}$ are the effective area of the membrane, the mass flow rate, and the specific heat capacity of the feed solution, respectively. The inlet and outlet hot feed temperatures are shown with $T_{b, f, \text { in }}$ and $T_{b, f, \text { out }}$, respectively.

\subsubsection{Temperature Polarization Coefficient (TPC)}

The ratio of the temperature difference at the membrane surface to the temperature difference in the bulk is defined as the thermal polarization coefficient or TPC. The DCMD module may have TPC equal to 1 ideally, but in the real systems, the TPC value is less than 1 (because of the temperature boundary layers). It is expressed as follows [29]:

$$
\operatorname{TPC}(\%)=\frac{T_{m, f}-T_{m, p}}{T_{b, f}-T_{b, p}} \times 100
$$

\section{Materials and Methods}

Low water production is one of the main challenges of DCMD process. To enhance the system performance, an innovative design of the DCMD module was developed. The modular or multi-staged design makes it possible to increase the heat flux by putting the plates together. Therefore, multi-staged direct contact membrane distillation (MDCMD) was considered in this study. The schematic of MDCMD of the present study is shown in Figure 2A. Noteworthily, the parallel (single-effect) and counter-current flow design membrane modules were considered in the present study. The fluid flow schematic of this consideration is shown in Figure 2B [30]. 


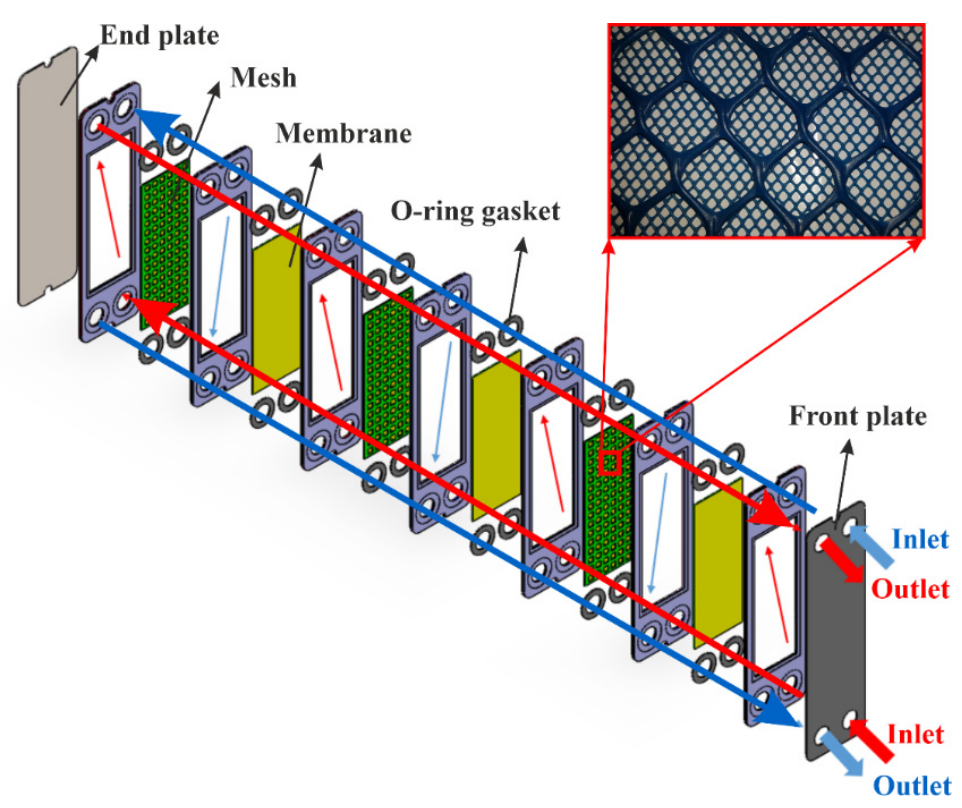

(A)

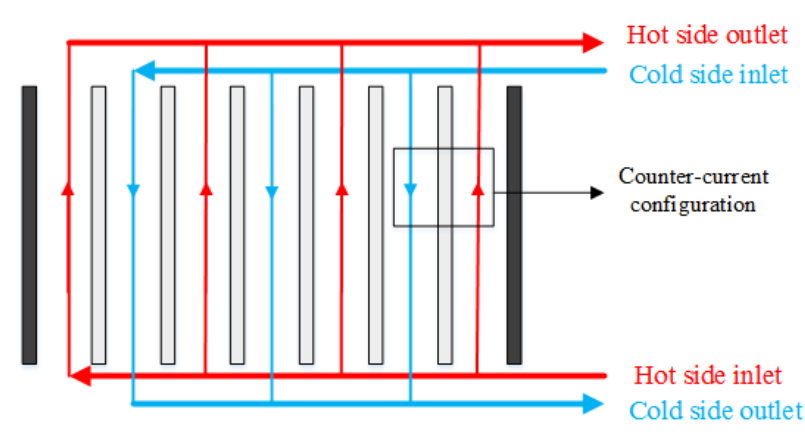

(B)

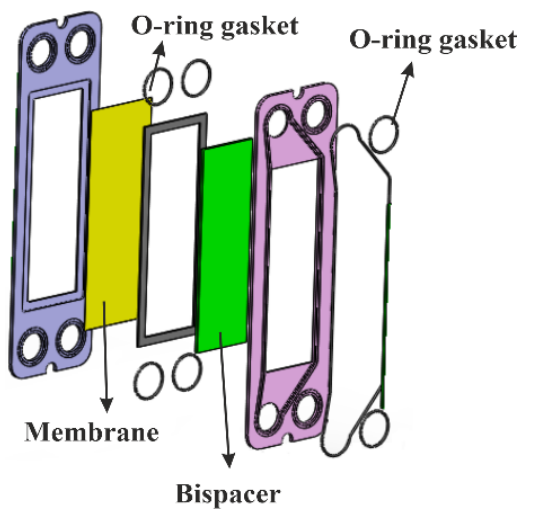

(C)

Figure 2. The schematic of multi-staged direct contact membrane distillation of the present study: (A) 3D schematic, (B) fluid flow schematic, (C) the Schematic of the position of the O-ring gasket.

As demonstrated in Figure 2A, different size spacers were put together. Since the spacers have different mesh sizes and filament diameters, implementing bispacer design in the MDCMD system improves mechanical stability, which assists in obtaining better working operation conditions such as higher feed flowrate.

As shown in Figure 2B, due to the counter-current design of the MDCMD system, the hot and cold side inlets were in opposite directions. The hot feed inlet stream and cold permeate stream enter through the down-side inlet and top-side inlet, respectively. The hot and cold streams flow inside the module, in parallel, through every other one by using an O-ring gasket, which seals the opposite inlet streams, as shown in Figure 2C. It has been shown in previous studies that this flow configuration effectively uses the temperature driving force and demonstrates higher permeate flux [16]. The details of the membrane and membrane module are presented in the following.

\subsection{Membrane and Membrane Module}

The design and construction of the membrane module was performed in Iran (Taha Ghaleb Toos Company, Mashhad, Iran), as shown in Figure 3. Tests were conducted using a commercial poly-tetra-fluoroethylene (PTFE) membrane with $190.19 \mathrm{~cm}^{2}$ effective area for one-staged and $950.95 \mathrm{~cm}^{2}$ for five-staged by Membrane Solution $(80 \%$ average porosity, 
$180-\mu \mathrm{m}$ thickness, $0.22-\mu \mathrm{m}$ average pore size, and approximate $100^{\circ}$ contact angle). The membrane was inserted between two symmetrical polyethylene (HD-PE) plates. Hence, two channels of $2 \mathrm{~mm}$ gap at both sides were created, which were sealed by silicone and rubber cords, as shown in parts A and B of Figure 3. The schematic and dimension of assembled plates are shown in Figure 3C.

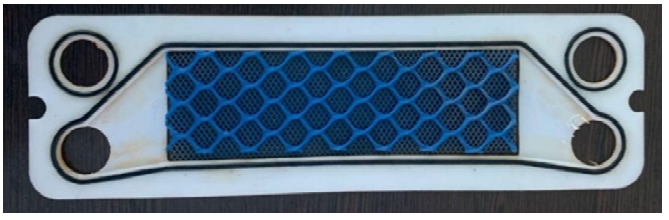

(A)

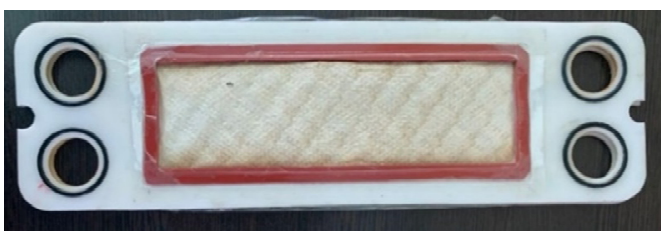

(B)

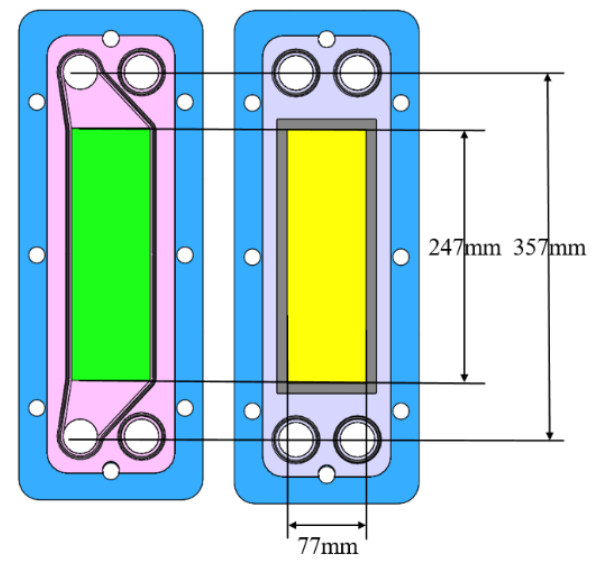

(C)

Figure 3. The plates: (A) channel plate, (B) membrane plate; $(\mathbf{C})$ the schematic with its dimensions.

The membrane is supported by a plastic net spacer. In addition, the net spacer promotes turbulence in the feed and permeate channels. In the present study, two kinds of spacers with large (spacer 1) and small (spacer 2) network layouts were used, as shown in parts A and B of Figure 4. Spacer 1 was placed in the channel plates to prevent excessive pressure drop in the process while creating turbulence in the channels. Spacer 2 was in contact with the membrane to provide good physical strength for the membrane. In addition, this spacer increases the Reynolds number and makes the boundary smaller; hence, the mean flux will be increased. Further details of both presented spacers are provided in Table 3.

\subsection{Experimental Procedure and Set Up}

The experiments were conducted in the IWET laboratory at the Center of Innovative Technology (CIT) center. Considering the experimental setup of Figure 5, the main module was responsible for mass transfer and wastewater treatment. The electrical heating element ( $3 \mathrm{KW}$ ) was used to provide the desired temperature of feed solution. Pure water was cooled by an air chiller and maintained at a temperature of $302 \pm 0.5 \mathrm{~K}$. The temperature and pressure of the input and output flows of the module were measured by temperature and pressure sensors. The flowmeters were used to maintain the required flow rate of both hot and cold streams. A conductivity/TDS sensor (EZDO 7200 with an accuracy of \pm 2 ppm; GONDO electronic, Taipei City, Taiwan) was used to measure the conductivity of the feed and permeate solutions at the outlet of the module to detect the leaks or pore wetting of the membrane. The pumps were capable of applying pressure up to 2 bar. Two storage tanks with a level meter were used to store feed and permeate. A make-up water tank was used to keep the salt concentration constant in the hot tank. The details of experimental setup is provided in Table 4. 


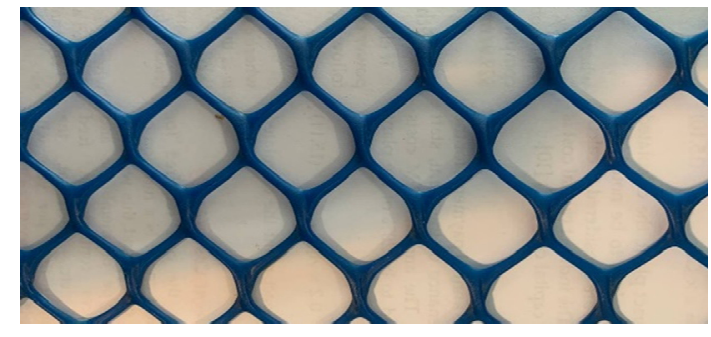

(A)

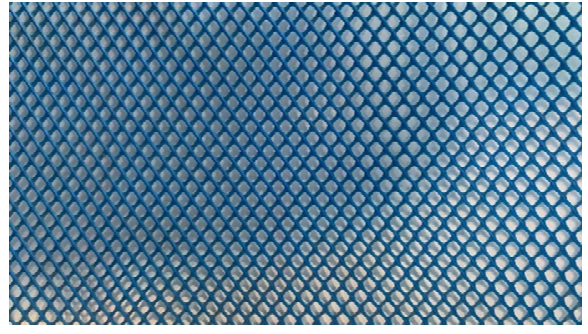

(B)

Figure 4. The proposed spacers: (A) spacer 1, (B) spacer 2.

Table 3. The specification of the spacers used in this study.

\begin{tabular}{cccccc}
\hline $\begin{array}{c}\text { Types of Spacer } \rightarrow \\
\text { Properties } \downarrow\end{array}$ & $\mathbf{1}$ & $\mathbf{2}$ & $\begin{array}{c}\text { Types of Spacer } \rightarrow \\
\text { Properties } \downarrow\end{array}$ & $\mathbf{1}$ \\
\hline Material & PP & PP & Angle between filaments $(\theta)(\mathrm{deg})$ & 90 & 90 \\
Thickness $\left(t_{\mathrm{s}}\right)(\mathrm{mm})$ & 1.8 & 1.25 & Mesh size $\left(l_{\mathrm{m}}\right)(\mathrm{mm})$ & 17.8 & 2.5 \\
Diameter of filament $\left(d_{f}\right)(\mathrm{mm})$ & 1.8 & 0.625 & & \\
\hline
\end{tabular}

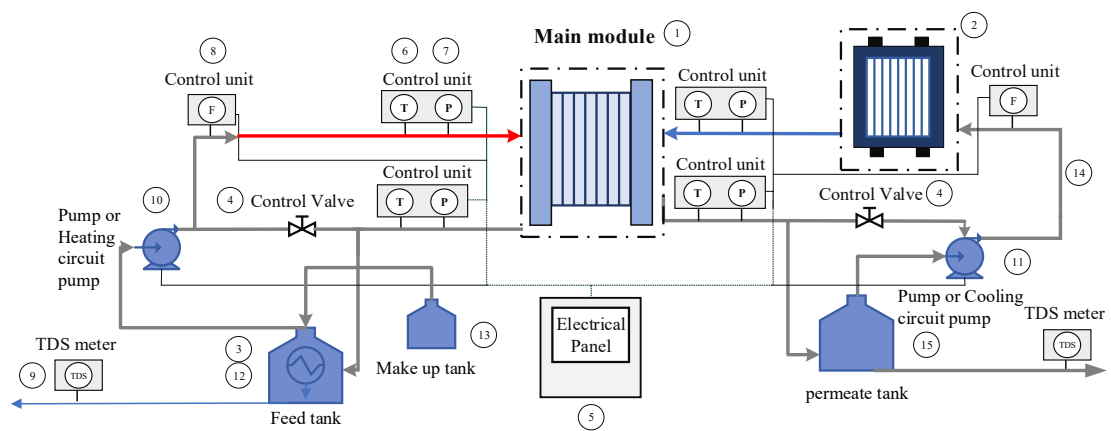

(A)

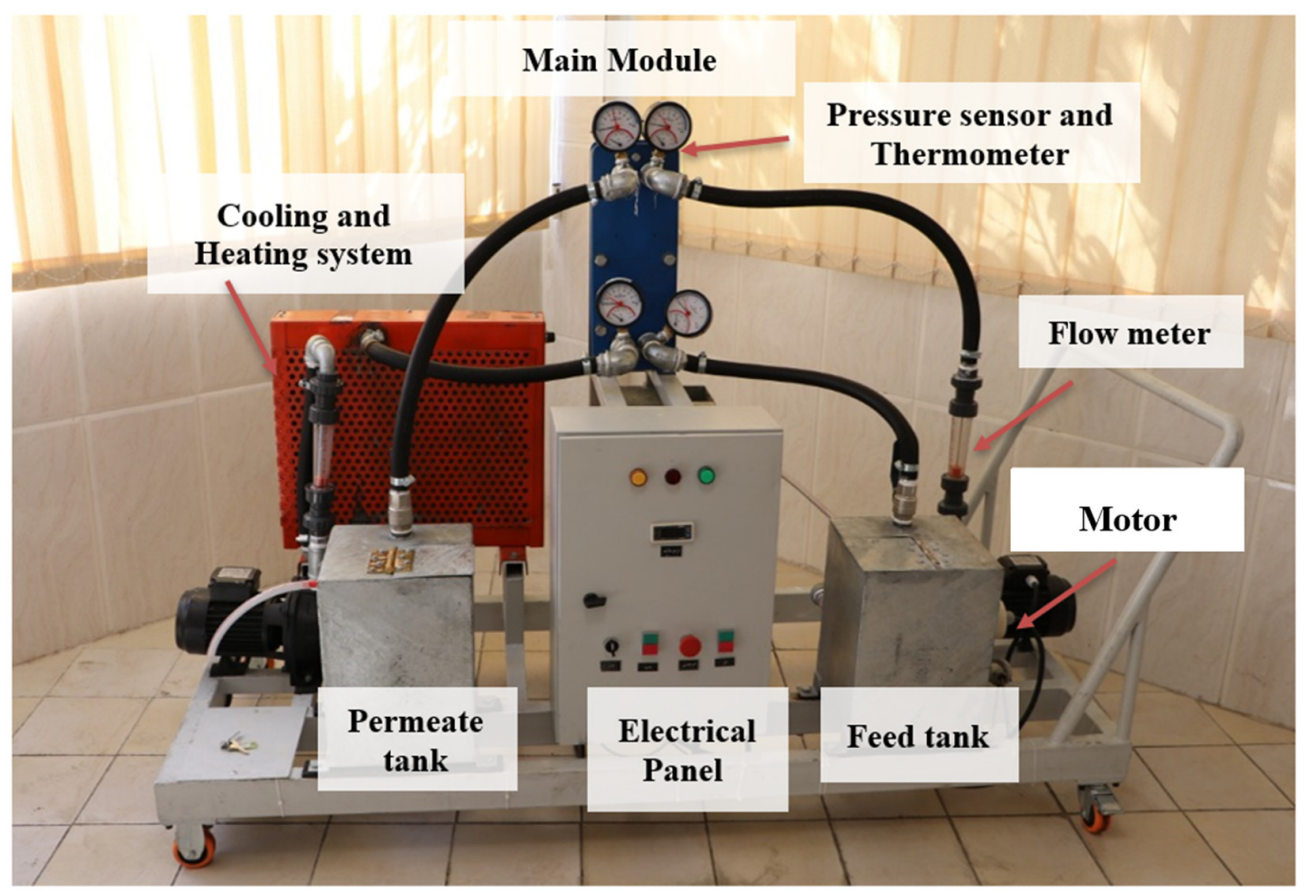

(B)

Figure 5. The experimental set up: (A) schematic, (B) IWET set up. 
Table 4. The experimental set up details.

\begin{tabular}{cccc}
\hline Number & Equipment & Number & Equipment \\
\hline$(1)$ & Main module & $(9)$ & TDS meter \\
$(2)$ & Air chiller & $(10)$ & Heating pump \\
$(3)$ & Element heater & $(11)$ & Cooling pump \\
$(4)$ & Control valve & $(12)$ & Feed tank \\
$(5)$ & Electrical panel & $(13)$ & Make up tank \\
$(6)$ & Thermometer & $(14)$ & Piping \\
$(7)$ & Pressure sensor & $(15)$ & Permeate tank \\
$(8)$ & Flow meter & & \\
\hline
\end{tabular}

\section{Results and Discussion}

A comprehensive experimental and analytical study on the effective feed side variables of the bispacer MDCMD system were considered in the current investigation. The feed side is always more effective than the permeate stream on the permeate flux, because it is the source of vaporization and controls the permeation process. In this section, the feed temperature $\left(T_{b, f}\right)$ was $313.15 \mathrm{~K}$ to $343.15 \mathrm{~K}$, and the influence of different flow rates (125 to $435 \mathrm{~L} / \mathrm{h}$ ) was examined. The feed salinity was varied 0.5 to $3.5 \%$. Additionally, the effect of stages on MDCMD performance was investigated by considering 1 to 5 stages. Note that all experiments were repeated two times, and the mean of results was considered in the study. The duration of the conducted experiment in each test was $90 \mathrm{~min}$ to ensure the steady-state condition was obtained.

\subsection{Effect of Feed Temperature}

The feed temperature's effect on the permeate flux was investigated experimentally and analytically (without and with spacers conditions), as shown in Figure 6. Other parameters were kept constant, including a flow rate of $200 \mathrm{~L} / \mathrm{h}$, salinity of $1.3 \%$, and permeate temperature of $302.15 \mathrm{~K}$. It should be noted that the salt removal percentage in all experiments was more than $99.99 \%$, which shows the high capability of the current MDCMD system in removing salt from saline effluents.

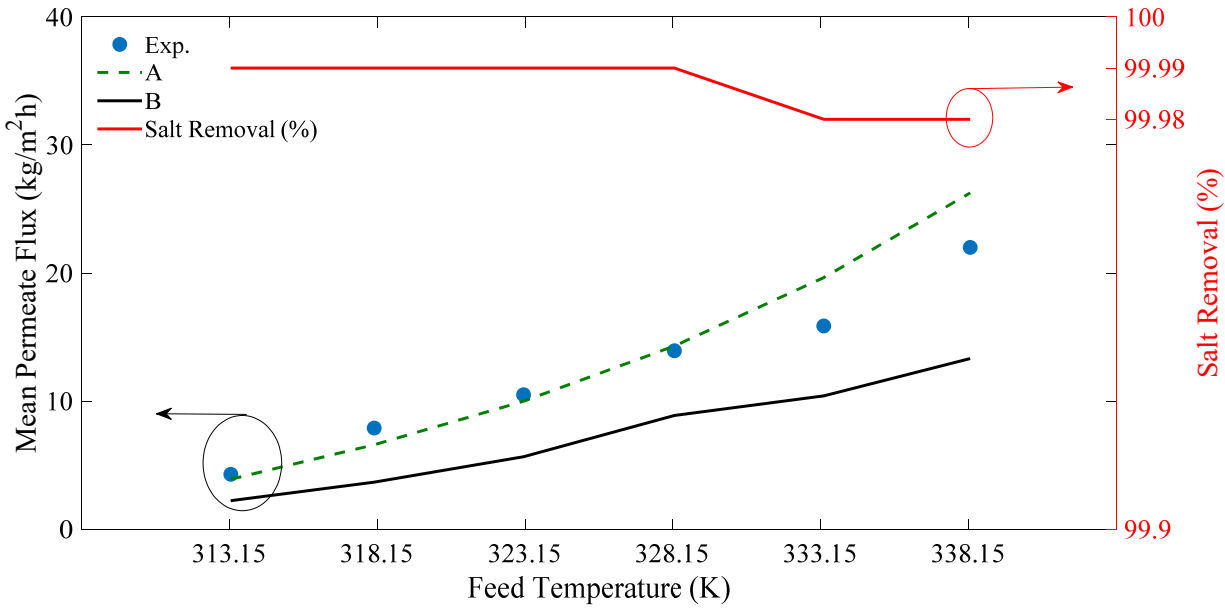

Figure 6. The permeate flux as a function of feed temperature with experimental and analytical ((A): with spacer; (B): without spacer) results.

Considering Figure 6, as the feed temperature increases, the mean permeate flux will increase. The permeate flux increases exponentially, which is in agreement with the Antonine Equation (19). The increase in the permeate flux with respect to feeding temperature is due to two phenomena. Firstly, an increase in temperature leads to an increase in partial vapor pressure, which is a driving force of the mass transfer mechanism. Therefore, the permeate flux is increased. Secondly, increasing the temperature enhances 
the kinetic energy of the molecules. As the kinetic energy increases, the liquid molecules convert to the vapor phase more quickly. Hence, the amount of permeate flux is increased by the temperature increment.

Considering Figure 6, the experimental permeate flux (Exp.) is higher than the analytical without spacer (B). To overcome this shortcoming, the analytical study considering the spacer (A) is presented in Figure 6, which is near to experimental results, which indicates the reduction of temperature difference between the membrane surface and the bulk. Therefore, more permeate flux can be provided. A previous study confirmed this finding [31].

\subsection{Effect of Feed Flow Rate}

The experimental and analytical results of permeate flux versus different feed flow rate are provided in Figure 7. The other conditions, including salinity, feed temperature, and permeate temperature, were $1.3 \%, 333.15 \mathrm{~K}$, and $302.15 \mathrm{~K}$, respectively, and remained constant during the process.

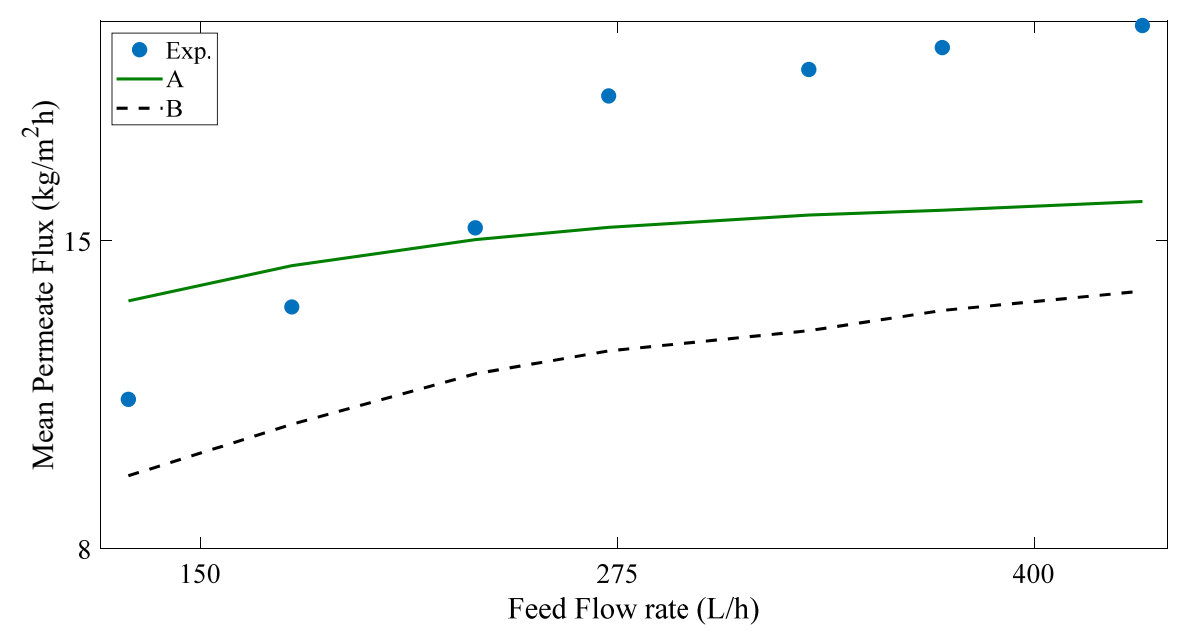

Figure 7. The permeate flux as a function of feed flow rate with experimental and analytical ((A): with spacer; (B): without spacer) results.

As shown in Figure 7, the increase of the feed flow rate leads to an increase of the permeate flux. Two phenomena are involved in permeate flux enhancement. Firstly, the Reynolds number of the feed stream increases with an increase of the feed flow rate. Hence, the turbulence of flow increases and affects temperature and concentration polarization. Secondly, increasing the feed flow rate leads to an increase of the average bulk temperature of the hot side, which provides a higher membrane temperature of the feed side. Therefore, more permeate flux was obtained by feed flow rate increment, because of both increasing flow turbulence and increasing feed temperature.

\subsection{Effect of Feed Salinity}

One of the feed parameters that affects permeate flux is salinity. To study this parameter, seven levels of salinity were tested, namely 0.5 to $3.5 \%$. The salt solution was prepared with $\mathrm{NaCl} \geq 99 \%$ purity. Feed and permeate flow rates were $200 \mathrm{~L} / \mathrm{h}$ and $100 \mathrm{~L} / \mathrm{h}$, respectively. The feed and permeate bulks temperatures were considered at $333.15 \mathrm{~K}$ and $302.15 \mathrm{~K}$, respectively. The mean permeate flux versus different salinity is shown in Figure 8. 


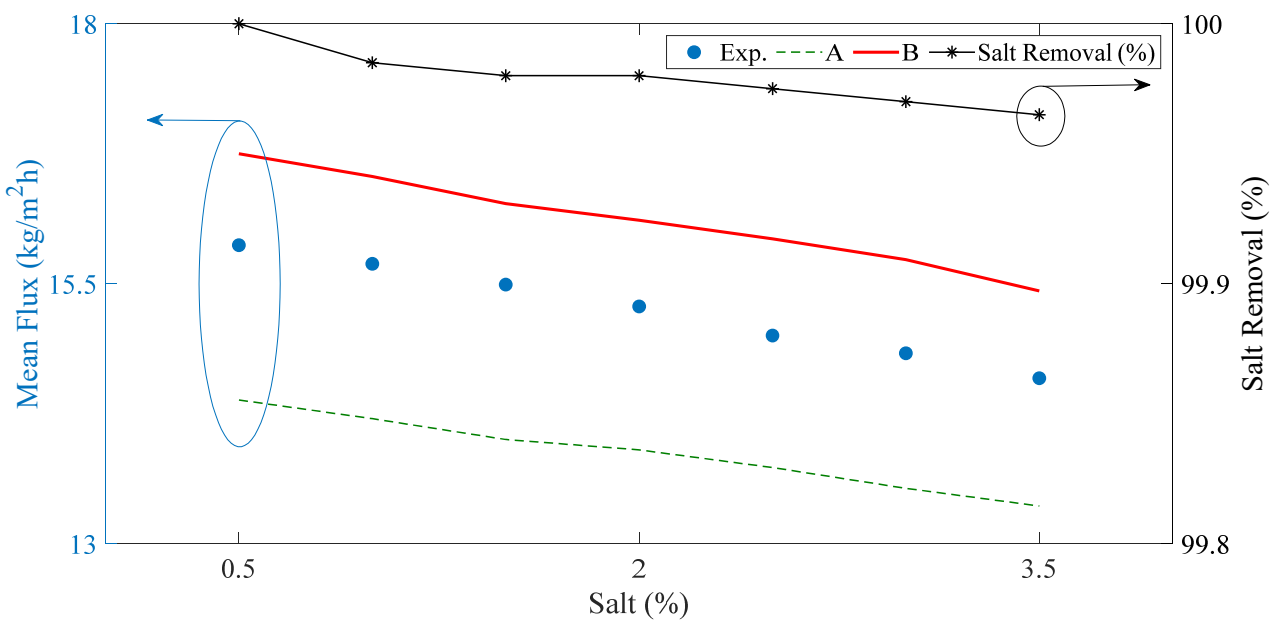

Figure 8. The permeate flux versus feed salinity with experimental and analytical ((A): with spacer; (B): without spacer) results.

As shown in Figure 8, an increase of feed salinity or concentration leads to a decrease of the permeate flux. Two main phenomena cause this result as follows: (1) The presence of $\mathrm{NaCl}$ molecules in water causes the formation of hydrogen bonds with water molecules, which increases the boiling point. Hence, more kinetic energy is needed to overcome the molecular bonds. Therefore, to convert the liquid phase into the vapor phase, the input energy should be increased. (2) The presence of salt ions in the aqueous phase creates additional resistance to the passage of vapor molecules through the membrane. Therefore, high feed salinity provides low mean flux.

\subsection{Effect of Number of Stages}

The operability of the current MDCMD was investigated in the previous sections. The effect of the number of stages is investigated in the current section. In order to provide the same conditions in all tests, the feed and permeate velocities were increased to provide the same Reynolds number in the flow channels of all samples. The permeate temperatures and salt concentrations constantly remained $302.15 \mathrm{~K}$ and $1.3 \%$ in all experiments, respectively. The results of the experimental for five stages with respect to feed temperature are provided in Figure 9.

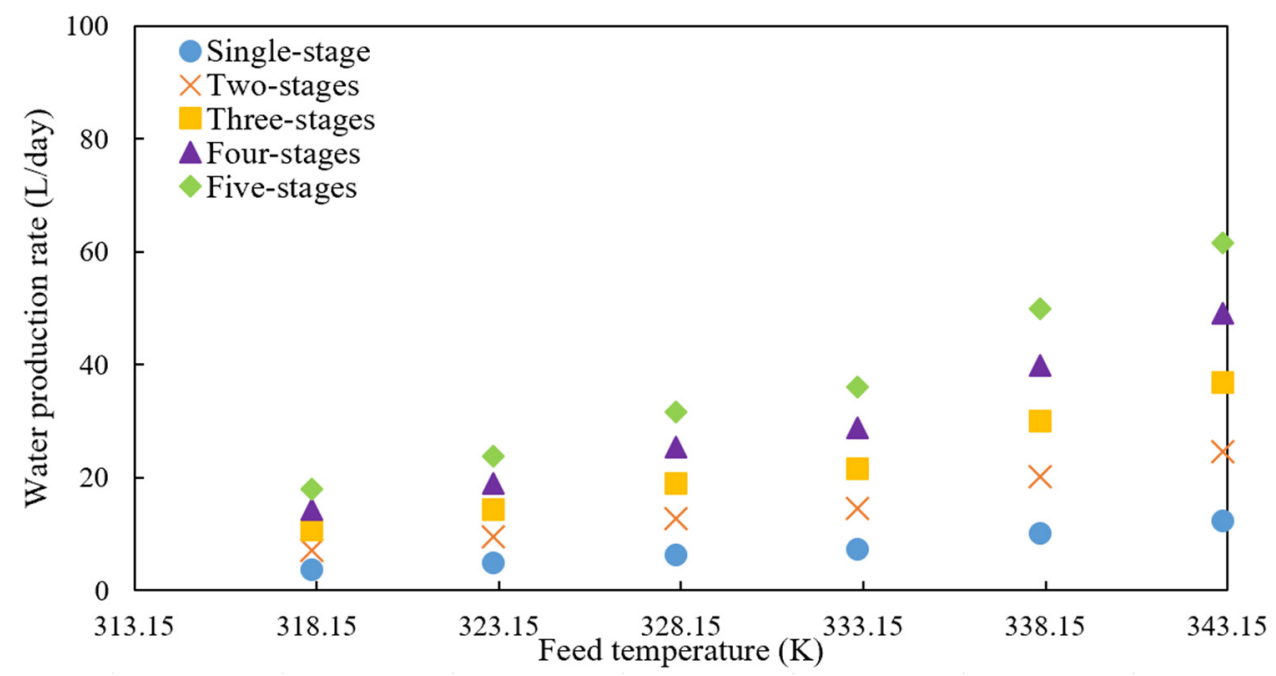

Figure 9. The daily water production versus the number of stages with experimental results. 
Considering Figure 9, as the stages of MDCMD increase, daily water production will increase. By increasing the number of mass transfer plates, the treatment capacity increases linearly (maintaining the conditions constant in the channels). This result, which is in agreement with single spacer MDCMD [19], indicates the ability to increase the capacity of the MD method in the designed module.

\subsection{The Efficiency}

To investigate the operability and sustainability of the presented bispacer MDCMD, different output efficiency parameters, including thermal efficiency $(\eta)$, gained output ratio (GOR), and temperature polarization coefficient (TPC), were studied in this section.

Considering salinity of $1.3 \%$, a permeate temperature of $302.15 \mathrm{~K}$ and flow rate of $200 \mathrm{~L} / \mathrm{h}$, the thermal efficiency or $\eta, G O R$, and TPC of the presented MDCMD with respect to variation of feed temperature are provided in Figure 10.

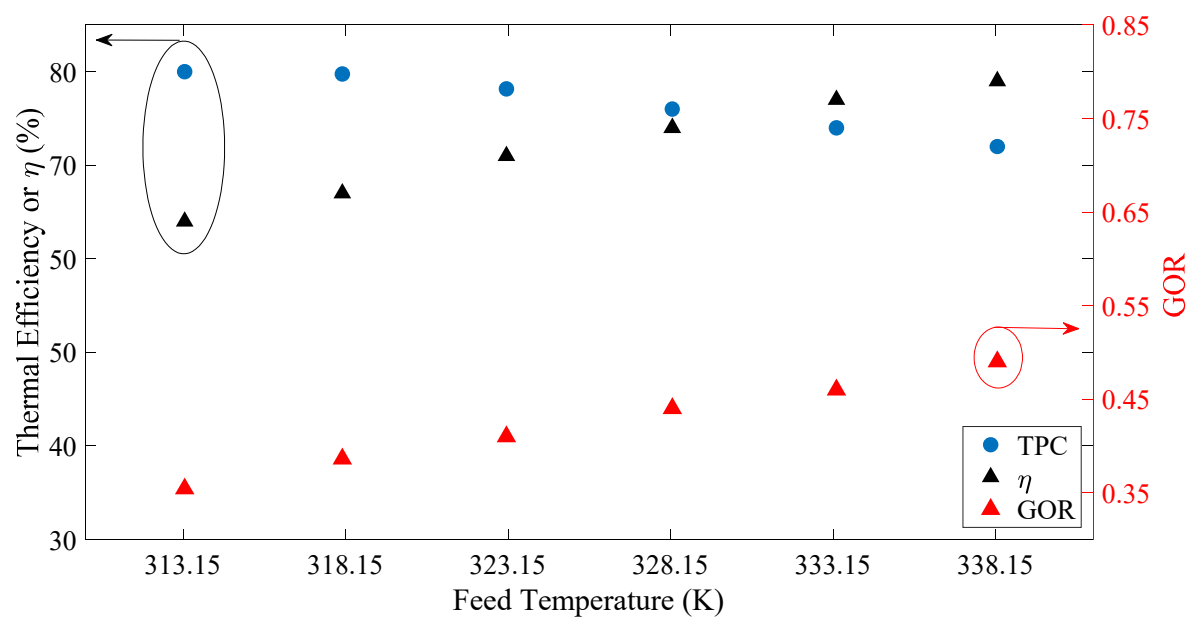

(A)

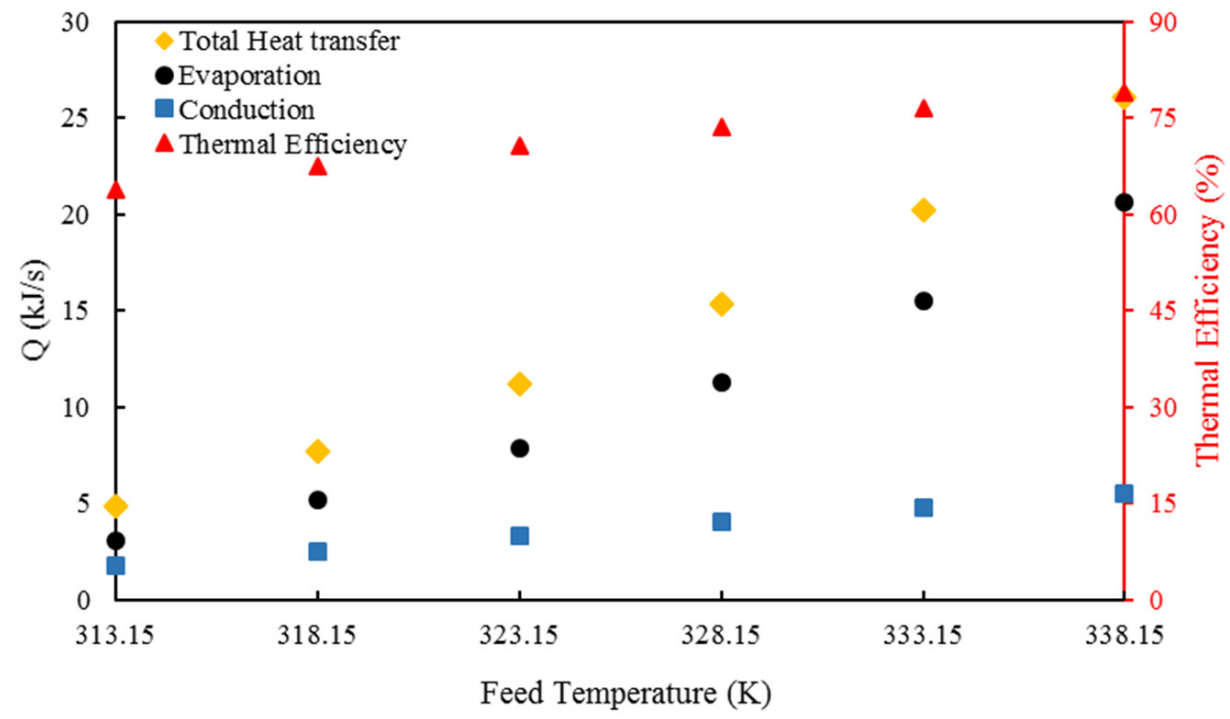

(B)

Figure 10. (A) The output efficiency parameters: thermal efficiency $(\eta)$, gained output ratio (GOR), and temperature polarization coefficient (TPC) of the presented bispacer MDCMD as a function of feed temperature; (B) the evaporation, conduction, and total heat transfer and thermal efficiency of the bispacer multi-staged DCMD system. 
As shown in Figure 10A, it was revealed that with the feed temperature increment, an increase in the thermal efficiency of the bispacer MDCMD was obtained. By increasing the feed temperature, both water evaporation inside pores and as a result permeate flux and conduction heat losses increase. However, the increasing slope of evaporation heat transfer is significantly higher than conduction heat transfer. The portion of the evaporation and the conduction heat transfer contribution to thermal efficiency is shown in Figure 10B and Equation (22). By increasing the feed temperature, the magnitude of the numerator has dramatically enhanced compared to conduction heat transfer, and as a result, the thermal efficiency increases. Therefore, the maximum thermal efficiency of $79 \%$ is achieved with the feed temperature of $338.15 \mathrm{~K}$.

In addition, an increase of feed temperature leads to an increase of the GOR. When feed temperature increases, the partial pressure difference increases. Hence, a larger mass flux will be provided. Considering Equation (23), the mass flux is proportional to GOR. Thus, with a feed temperature of $338.15 \mathrm{~K}$, the maximum GOR is provided.

Furthermore, the increase of feed temperature results in a decrease of temperature polarization coefficient (TPC), as shown in Figure 10. The feed temperature or bulk feed temperature is related to TPC inversely based on Equation (24). As a result, the maximum TPC of $80 \%$ is achieved when the feed temperature is $313.15 \mathrm{~K}$.

\section{Conclusions}

A new bispacer multi-staged direct contact membrane distillation (MDCMD) is presented in the current study. Bispacer configuration had a significant effect on increasing mechanical stability and turbulence. An analytical approach is considered using heat transfer, mass transfer, and conservation energy. It was revealed that an increase of feed temperature and feed flow rate lead to an increase of the permeate flux of both experimental and analytical results. The experimental and analytical results showed that enhancing feed salinity decreases the permeate flux. Furthermore, with the increase of stages, higher permeate flux was obtained. It is worth noting that the error between analytical and experimental results was reduced due to the considered spacer in the analytical approach. Moreover, it is shown that an increase in temperature increases thermal efficiency and GOR, while it decreases TPC. Interestingly, the thermal efficiency of $79 \%$ is provided with a temperature of $338.15 \mathrm{~K}$ with the presented bispacer MDCMD. As a result, the current study presents reliable results for a scaled-up MDCMD module to construct a more useful desalination system using a bispacer configuration for the water recovery demand.

Author Contributions: Conceptualization, H.G.; methodology, M.A.; software, S.S.M.; validation, M.A.; formal analysis, M.A.; investigation, M.A., M.H.F. and S.F.N.; resources, M.A. and S.F.N.; data curation, S.A.P. and M.A.; writing-original draft preparation, M.A., M.H.F. and S.F.N.; writingconsultation on methodology and system design, review and editing, F.M. and A.A.; supervision, A.F.; project administration, M.H.F.; funding acquisition, A.F. All authors have read and agreed to the published version of the manuscript.

Funding: This research received no external funding.

Data Availability Statement: Data available on request due to restrictions eg privacy or ethical. The data are not publicly available due to the law of TGT Co.'s policy, who is owner of IWET lab.

Acknowledgments: This work has been supported by Taha Ghaleb Toos (TGT) Co., Center of Innovative Technology (CIT), under grant number 2021.03.08WTR01.

Conflicts of Interest: The authors declare no conflict of interest. 


\section{Nomenclature}

\begin{tabular}{|c|c|c|}
\hline Parameter & Definition & Unit \\
\hline$P$ & Mean vapor pressure of the membrane & $\mathrm{Pa}$ \\
\hline $\mathrm{Pa}$ & Entrapped air pressure & $\mathrm{Pa}$ \\
\hline$P_{0}$ & Vapor pressure of pure water & $\mathrm{Pa}$ \\
\hline$P_{1}$ & Vapor pressure at feed membrane surface & $\mathrm{Pa}$ \\
\hline$P_{2}$ & Vapor pressure at permeates membrane surface & $\mathrm{Pa}$ \\
\hline $\operatorname{Pr}$ & Prandtl number & - \\
\hline$Q$ & Heat flux & $\mathrm{W} / \mathrm{m}^{2}$ \\
\hline$R$ & Gas constant & $\mathrm{J} / \mathrm{kg} \cdot \mathrm{K}$ \\
\hline $\operatorname{Re}$ & Reynolds number & - \\
\hline$S$ & Mean free path of the transferred gas molecule & $\mathrm{m}$ \\
\hline$T_{b, f}$ & Bulk feed side temperature & K \\
\hline$T_{b, p}$ & Bulk permeate side temperature & K \\
\hline$T_{p, f}$ & Temperature at the hot membrane surface & K \\
\hline$T_{m, p}$ & Temperature at cold membrane surface & $\mathrm{K}$ \\
\hline$U$ & The overall heat transfer through the membrane & $\mathrm{W} / \mathrm{m}^{2} \cdot \mathrm{K}$ \\
\hline$X_{w}$ & Weight fraction of water & - \\
\hline$X_{\mathrm{NaCl}}$ & Weight fraction of $\mathrm{NaCl}$ & - \\
\hline$\delta$ & Membrane thickness & $\mathrm{m}$ \\
\hline$\varepsilon$ & Membrane porosity & $\%$ \\
\hline$\mu$ & Kinematic viscosity & $\mathrm{Pa} \cdot \mathrm{s}$ \\
\hline$v$ & Dynamic viscosity & $\mathrm{Pa} \cdot \mathrm{s}$ \\
\hline$\tau$ & Membrane tortuosity & - \\
\hline$\gamma$ & Coefficient of activity & - \\
\hline$\rho$ & Density & $\mathrm{Kg} / \mathrm{m}^{3}$ \\
\hline TPC & Thermal polarization coefficient & - \\
\hline$q_{S T E C}$ & Specific thermal energy consumption & $\mathrm{J} \cdot \mathrm{s} / \mathrm{m}^{3}$ \\
\hline$\eta$ & Thermal efficiency & - \\
\hline$a_{w}$ & Activity of water & - \\
\hline$C_{m}$ & Membrane mass flux coefficient & $\mathrm{kg} / \mathrm{m}^{2} \cdot \mathrm{Pa} \cdot \mathrm{h}$ \\
\hline$c_{p}$ & Specific heat coefficient & $\mathrm{J} / \mathrm{kg} \cdot \mathrm{K}$ \\
\hline$D$ & Diffusion coefficient & - \\
\hline$d_{e}$ & Collision diameter of the water vapor and air & $\mathrm{m}$ \\
\hline$d_{h}$ & Hydraulic diameter in empty channel & $\mathrm{m}$ \\
\hline$d_{h s}$ & Hydraulic diameter in spacer-filled channel & $\mathrm{m}$ \\
\hline$d_{p}$ & Membrane pore diameter & $\mathrm{m}$ \\
\hline GOR & Gained output ratio & - \\
\hline$h_{f}$ & Heat transfer coefficient at feed side & $\mathrm{W} / \mathrm{m}^{2} \cdot \mathrm{K}$ \\
\hline$h_{m}$ & Heat transfer coefficient of the membrane & $\mathrm{W} / \mathrm{m}^{2} \cdot \mathrm{K}$ \\
\hline$h_{p}$ & Heat transfer coefficient at permeate side & $\mathrm{W} / \mathrm{m}^{2} \cdot \mathrm{K}$ \\
\hline$H_{v}$ & Vaporization enthalpy of water at the mean temperature & $\mathrm{kJ} / \mathrm{kg}$ \\
\hline$J$ & Total mass flux of the membrane & $\mathrm{kg} / \mathrm{m}^{2} \cdot \mathrm{h}$ \\
\hline$k$ & Thermal conductivity of fluid & $\mathrm{W} / \mathrm{m} \cdot \mathrm{k}$ \\
\hline$k_{B}$ & Boltzmann constant & $\mathrm{J} / \mathrm{K}$ \\
\hline$k_{g}$ & Vapor-air heat transfer coefficient & $\mathrm{W} / \mathrm{m} \cdot \mathrm{k}$ \\
\hline$k_{m}^{\circ}$ & Membrane heat transfer coefficient & $\mathrm{W} / \mathrm{m} \cdot \mathrm{k}$ \\
\hline$k n$ & Knudsen number & \\
\hline$k_{s}$ & PTFE heat transfer coefficient & $\mathrm{W} / \mathrm{m} \cdot \mathrm{k}$ \\
\hline$L$ & Channel length & $\mathrm{m}$ \\
\hline$l_{m}$ & Mesh size & $\mathrm{m}$ \\
\hline LMTD & Log mean temperature coefficient & $\mathrm{K}$ \\
\hline M & Molecular weight & $\mathrm{kg} /$ mole \\
\hline$N u$ & Nusselt number & - \\
\hline$T_{b, f, \text { in }}$ & Inlet hot feed temperatures & $\mathrm{K}$ \\
\hline$T_{b, f \text { out }}$ & Outlet hot feed temperatures & K \\
\hline
\end{tabular}




\section{Appendix A}

Flow direction

Flow direction

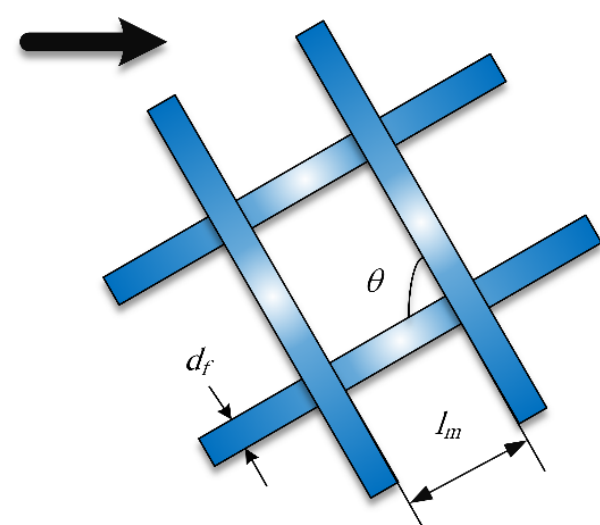

(a)

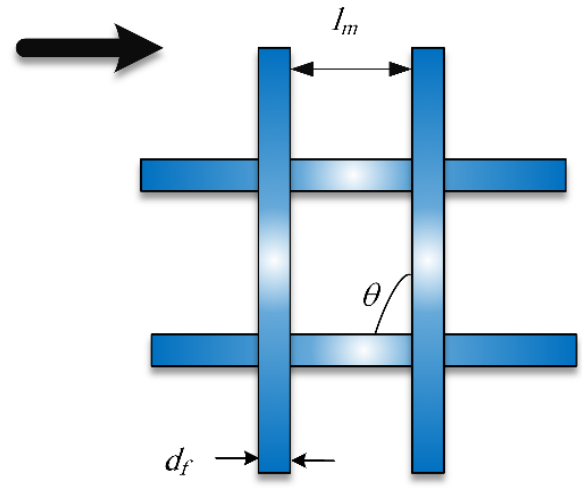

(b)

Figure A1. Spacer's structure; (a) Spacer changes flow direction, (b) Spacers do not change flow direction [14].

The Nu number correlation for spacer-filled channels in DCMD is obtained from [32].

$$
N u=0.66 k_{d c} \operatorname{Re}^{0.5} \operatorname{Pr}^{0.33}\left(\frac{2 d_{h s}}{l_{m}}\right)^{0.5}
$$

and

$$
k_{d c}=1.654\left(\frac{d_{f}}{t_{s}}\right)^{-0.039} \varepsilon^{0.75}\left(\sin \left(\frac{\theta}{2}\right)\right)^{0.086}
$$

The Reynolds and Prandtl number are defined in Equations (3) and (4), respectively.

$$
\begin{gathered}
\operatorname{Re}=\frac{\rho u_{s} d_{h s}}{\mu} \\
\operatorname{Pr}=\frac{\mu C_{p}}{k}
\end{gathered}
$$

Flow velocity and hydraulic diameter of spacer-filled channels and hydraulic diameter are determined with Equations (5) and (6), respectively:

$$
\begin{gathered}
u_{s}=\frac{V}{W \times t_{s} \times \varepsilon} \\
d_{h s}=\frac{4 \varepsilon}{(2(W+t) / W t)+\mid(1-\varepsilon) S_{v s p}}
\end{gathered}
$$

$S_{v s p}$ is the specific surface of the spacers, and $\varepsilon$ is the spacer voidage, calculated by:

$$
\begin{gathered}
S_{v s p}=\frac{4}{d_{f}} \\
\varepsilon=1-\frac{\pi d_{f}^{2}}{2 l_{m} t_{s} \sin \theta}
\end{gathered}
$$

\section{Appendix B}

The flowchart of the iterative procedure to calculate $T_{m, f}$, and $T_{m, p}$ is shown in Figure A2. At first, it is assumed that $T_{m, f}$, and $T_{m, p}$ are equal to the bulk temperature 
of the hot $\left(T_{b, f}\right)$ and cold side $\left(T_{b, p}\right)$. Then, by defining geometrical parameters and physical properties of the hot and cold streams, the heat transfer coefficients for both streams were calculated and used to determine the updated value of $T_{m, f}$, and $T_{m, p}$. The iterative procedure of the analytical model continues until the assumed temperatures are equal to the updated ones. By calculating $T_{m, f}$, and $T_{m, p}$, the theoretical values of other parameters (such as permeate flux, GOR, thermal efficiency, and TPC) can be obtained [33].

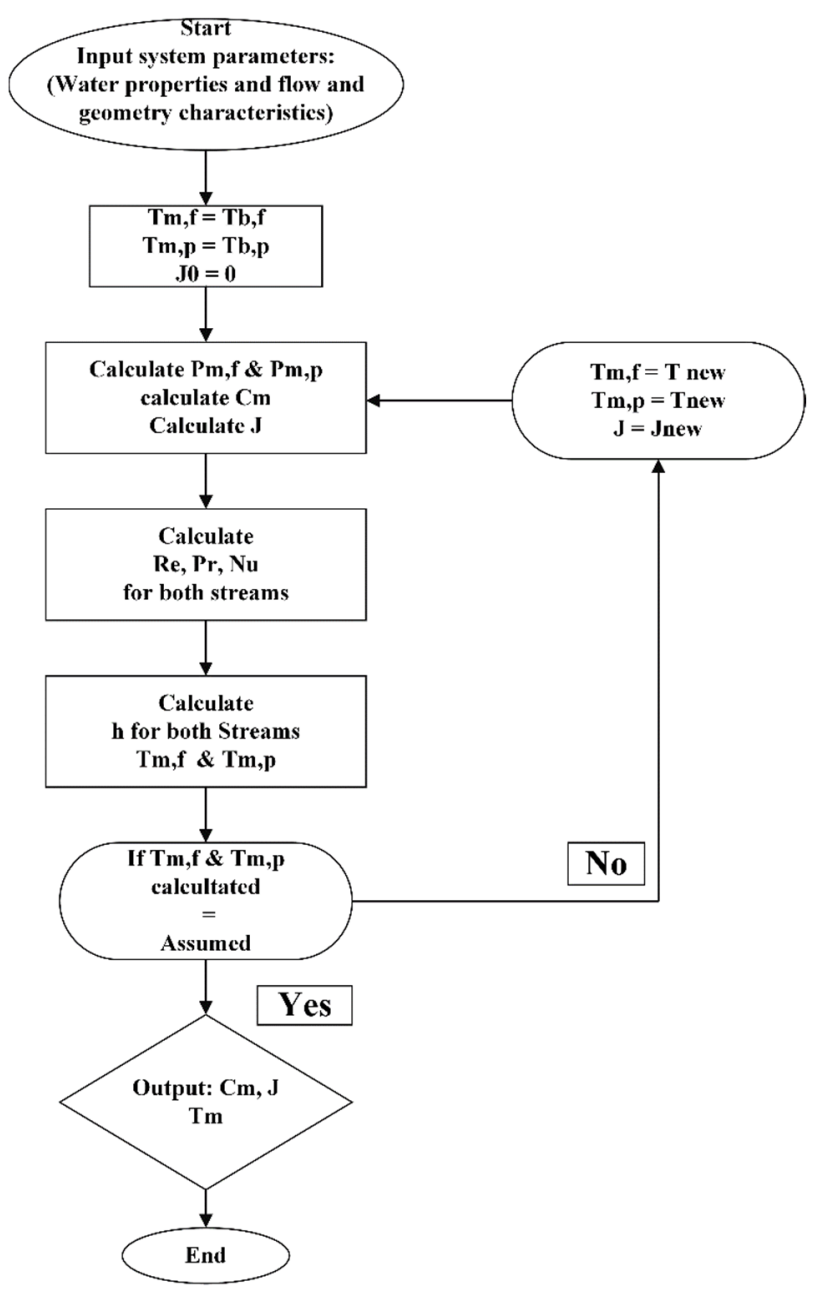

Figure A2. Here $J_{\exp }$ and $J_{\mathrm{Th}}$ are the permeate flux of experimental and theoretical results, respectively. Noteworthily, the experimental permeate flux was compared with theoretical results (with and without spacer) for various feed temperatures, flow rates, and concentrations in Tables A1-A3, respectively.

Table A1. The error of experimental and theoretical ((A) with, and (B) without spacer) of permeate flux for different feed temperatures.

\begin{tabular}{|c|c|c|c|c|c|c|}
\hline \multirow{2}{*}{ Run } & \multirow{2}{*}{ Feed Temperature (K) } & \multirow{2}{*}{ Flux $_{\text {Exp. }}\left(\mathrm{kg} / \mathrm{m}^{2} \mathrm{~h}\right)$} & \multicolumn{2}{|c|}{ Flux $_{\text {Th. }}\left(\mathrm{kg} / \mathrm{m}^{2} \mathrm{~h}\right)$} & \multicolumn{2}{|c|}{ Error \% } \\
\hline & & & A & B & A & B \\
\hline 1 & 313.15 & 4.3 & 3.9 & 2.13 & 9.3 & 50.46 \\
\hline 2 & 318.15 & 7.9 & 6.62 & 3.67 & 16.2 & 53.54 \\
\hline 3 & 323.15 & 10.5 & 9.63 & 5.51 & 8.28 & 47.52 \\
\hline 4 & 328.15 & 13.93 & 13.82 & 8.67 & 0.79 & 37.76 \\
\hline 5 & 333.15 & 15.87 & 19.19 & 10.22 & 20.92 & 35.6 \\
\hline 6 & 338.15 & 22 & 25.88 & 12.79 & 17.64 & 41.86 \\
\hline
\end{tabular}


Table A2. The error of experimental and theoretical (with and without spacer) of permeate flux for different feed flow rate.

\begin{tabular}{|c|c|c|c|c|c|c|}
\hline \multirow{2}{*}{ Run } & \multirow{2}{*}{ Feed Flow Rate (L/h) } & \multirow{2}{*}{$\operatorname{Flux}_{\operatorname{Exp} .}\left(\mathrm{kg} / \mathrm{m}^{2} \mathrm{~h}\right)$} & \multicolumn{2}{|c|}{$\operatorname{Flux}_{\text {The. }}\left(\mathrm{kg} / \mathrm{m}^{2} \mathrm{~h}\right)$} & \multicolumn{2}{|c|}{ Error \% } \\
\hline & & & A & B & A & B \\
\hline 1 & 125 & 11.4 & 13.64 & 9.66 & 19.64 & 15.26 \\
\hline 2 & 175 & 13.5 & 14.44 & 10.83 & 6.9 & 19.77 \\
\hline 3 & 235 & 15.3 & 15.03 & 11.98 & 1.7 & 21.7 \\
\hline 4 & 275 & 17.2 & 15.31 & 12.5 & 10.99 & 27.32 \\
\hline 5 & 325 & 18.9 & 15.59 & 12.96 & 17.51 & 31.42 \\
\hline 6 & 375 & 19.4 & 15.7 & 13.42 & 19.07 & 30.82 \\
\hline 7 & 435 & 19.9 & 15.9 & 13.86 & 20.1 & 30.35 \\
\hline
\end{tabular}

Table A3. The error of experimental and theoretical (with and without spacer) of permeate flux for different salt concentration.

\begin{tabular}{cccccc}
\hline \multirow{2}{*}{ Salt (\%) } & \multirow{2}{*}{ Flux $_{\text {Exp. }}\left(\mathbf{k g} / \mathbf{m}^{\mathbf{2}} \mathbf{h}\right)$} & \multicolumn{2}{c}{ Flux $_{\text {Th. }}$} & \multicolumn{2}{c}{ Error $\mathbf{0}$} \\
\cline { 3 - 6 } & 15.87 & $\mathbf{A}$ & $\mathbf{B}$ & $\mathbf{A}$ & $\mathbf{B}$ \\
\hline 0.5 & 15.69 & 14.57 & 7.98 & 8.19 & 49.71 \\
\hline 1 & 15.49 & 14.4 & 7.89 & 8.22 & 49.71 \\
\hline 1.5 & 15.28 & 14.04 & 7.69 & 8.11 & 49.67 \\
\hline 2 & 15.00 & 13.83 & 7.58 & 7.8 & 49.46 \\
\hline 2.5 & 14.83 & 13.63 & 7.46 & 8.09 & 49.69 \\
\hline 3 & & & &
\end{tabular}

\section{References}

1. Negewo, B.D. Renewable Energy Desalination: An Emerging Solution to Close the Water Gap in the Middle East and North Africa; World Bank Publications: Washington, DC, USA, 2012.

2. Ali, A.; Macedonio, F.; Drioli, E.; Aljlil, S.; Alharbi, O. Experimental and theoretical evaluation of temperature polarization phenomenon in direct contact membrane distillation. Chem. Eng. Res. Design 2013, 91, 1966-1977. [CrossRef]

3. Mahmoudi, F.; Goodarzi, G.M.; Dehghani, S.; Akbarzadeh, A. Experimental and theoretical study of a lab scale permeate gap membrane distillation setup for desalination. Desalination 2017, 419, 197-210. [CrossRef]

4. Tomaszewska, M. Membrane distillation-examples of applications in technology and environmental protection. Pol. J. Environ. Stud. 2000, 9, 27-36.

5. García-Payo, M.; Izquierdo-Gil, M.A.; Fernández-Pineda, C. Air gap membrane distillation of aqueous alcohol solutions. J. Membr. Sci. 2000, 169, 61-80. [CrossRef]

6. Ali, E.; Orfi, J.; Najib, A. Assessing the thermal efficiency of brackish water desalination by membrane distillation using exergy analysis. Arab. J. Sci. Eng. 2018, 43, 2413-2424. [CrossRef]

7. Zhao, K.; Heinzl, W.; Wenzel, M.; Büttner, S.; Bollen, F.; Lange, G.; Heinzl, S.; Sarda, N. Experimental study of the memsys vacuum-multi-effect-membrane-distillation (V-MEMD) module. Desalination 2013, 323, 150-160. [CrossRef]

8. Andrés-Mañas, J.; Ruiz-Aguirre, A.; Acién, F.; Zaragoza, G. Performance increase of membrane distillation pilot scale modules operating in vacuum-enhanced air-gap configuration. Desalination 2020, 475, 114202. [CrossRef]

9. Alkhudhiri, A.; Darwish, N.; Hilal, N. Membrane distillation: A comprehensive review. Desalination 2012, 287, 2-18. [CrossRef]

10. Khayet, M. Membranes and theoretical modeling of membrane distillation: A review. Adv. Colloid Interface Sci. 2011, 164, 56-88. [CrossRef]

11. Manawi, Y.M.; Khraisheh, M.; Fard, A.K.; Benyahia, F.; Adham, S. Effect of operational parameters on distillate flux in direct contact membrane distillation (DCMD): Comparison between experimental and model predicted performance. Desalination 2014, 336, 110-120. [CrossRef]

12. Khalifa, A.; Ahmad, H.; Antar, M.; Laoui, T.; Khayet, M. Experimental and theoretical investigations on water desalination using direct contact membrane distillation. Desalination 2017, 404, 22-34. [CrossRef]

13. Zhang, J.; Gray, S. Modelling heat and mass transfers in DCMD using compressible membranes. J. Membr. Sci. 2012, 387, 7-16. [CrossRef] 
14. Ve, Q.L.; Rahaoui, K.; Bawahab, M.; Faqeha, H.; Date, A.; Akbarzadeh, A.; Do, M.C.; Nguyen, Q.L. Experimental investigation of heat transfer correlation for direct contact membrane distillation. J. Heat Transf. 2020, 142, 012001. [CrossRef]

15. Ve, Q.L.; Koirala, R.; Bawahab, M.; Faqeha, H.; Do, M.C.; Nguyen, Q.L.; Date, A.; Akbarzadeh, A. Experimental investigation of the effect of the spacer and operating conditions on mass transfer in direct contact membrane distillation. Desalination 2020, 114839. [CrossRef]

16. Alsaadi, A.S.; Ghaffour, N.; Li, J.-D.; Gray, S.; Francis, L.; Maab, H.; Amy, G.L. Modeling of air-gap membrane distillation process: A theoretical and experimental study. J. Membr. Sci. 2013, 445, 53-65. [CrossRef]

17. Ameen, N.A.M.; Ibrahim, S.S.; Alsalhy, Q.F.; Figoli, A. Highly Saline Water Desalination Using Direct Contact Membrane Distillation (DCMD): Experimental and Simulation Study. Water 2020, 12, 1575. [CrossRef]

18. Wang, P.; Chung, T.-S. Recent advances in membrane distillation processes: Membrane development, configuration design and application exploring. J. Membr. Sci. 2015, 474, 39-56. [CrossRef]

19. Ibrahim, S.S.; Alsalhy, Q.F. Modeling and simulation for direct contact membrane distillation in hollow fiber modules. AIChE J. 2013, 59, 589-603. [CrossRef]

20. Janajreh, I.; Suwwan, D.; Hashaikeh, R. Assessment of direct contact membrane distillation under different configurations, velocities and membrane properties. Appl. Energy 2017, 185, 2058-2073. [CrossRef]

21. Lawal, D.U.; Khalifa, A.E. Flux prediction in direct contact membrane distillation. Int. J. Mater. Mech. Manuf. 2014, 2, 302-308. [CrossRef]

22. Sanmartino, J.A.; Khayet, M.; García-Payo, M.; Hankins, N.; Singh, R. Desalination by Membrane Distillation; Elsevier: Amsterdam, The Netherlands, 2016.

23. Das, S.K. General dusty gas model for porous media with a specified pore size distribution. Chem. Eng. Sci. 2019, $203,293-301$. [CrossRef]

24. El-Bourawi, M.; Ding, Z.; Ma, R.; Khayet, M. A framework for better understanding membrane distillation separation process. J. Membr. Sci. 2006, 285, 4-29. [CrossRef]

25. Essalhi, M.; Khayet, M. Self-sustained webs of polyvinylidene fluoride electrospun nanofibers at different electrospinning times: 2. Theoretical analysis, polarization effects and thermal efficiency. J. Membr. Sci. 2013, 433, 180-191. [CrossRef]

26. Lawson, K.W.; Lloyd, D.R. Membrane distillation. J. Membr. Sci. 1997, 124, 1-25. [CrossRef]

27. Chen, T.-C.; Ho, C.-D.; Yeh, H.-M. Theoretical modeling and experimental analysis of direct contact membrane distillation. J. Membr. Sci. 2009, 330, 279-287. [CrossRef]

28. Duong, H.C.; Cooper, P.; Nelemans, B.; Cath, T.Y.; Nghiem, L.D. Optimising thermal efficiency of direct contact membrane distillation by brine recycling for small-scale seawater desalination. Desalination 2015, 374, 1-9. [CrossRef]

29. Criscuoli, A. Improvement of the Membrane Distillation performance through the integration of different configurations. Chem. Eng. Res. Des. 2016, 111, 316-322. [CrossRef]

30. Burhan, M.; Shahzad, M.W.; Ybyraiymkul, D.; Oh, S.J.; Ghaffour, N.; Ng, K.C. Performance investigation of MEMSYS vacuum membrane distillation system in single effect and multi-effect mode. Sustain. Energy Technol. Assess. 2019, 34, 9-15. [CrossRef]

31. Dutta, N.; Singh, B.; Subbiah, S.; Muthukumar, P. Performance analysis of a single and multi-staged direct contact membrane distillation module integrated with heat recovery units. Chem. Eng. J. Adv. 2020, 4, 100055. [CrossRef]

32. Da Costa, A.R. Fluid Flow and Mass Transfer in Spacer-Filled Channels for Ultrafiltration; University of New South Wales: Kensington, Australia, 1993.

33. Nakoa, K.; Rahaoui, K.; Date, A.; Akbarzadeh, A. An experimental review on coupling of solar pond with membrane distillation. Sol. Energy 2015, 119, 319-331. [CrossRef] 